\title{
CORRUPTION AND TRADE IN GENERAL EQUILIBRIUM*
}

\author{
Sugata Marjit \\ Centre For Studies in Social Science, Calcutta, India \\ and \\ Biswajit Mandal \\ Visva Bharati University, Santiniketan, India
}

\begin{abstract}
$\underline{\text { ABSTRACT }}$
We use the Heckscher - Ohlin - Samuelson-Vanek (HOSV) model of international trade to find out a link between corruption and the pattern of trade, not just its effect on the volume of trade, the usual point of query in the existing literature. We prove that greater corruption in labor-abundant countries will restrict the volume of world trade by working against the factor endowment bias. This is caused by a class of intermediaries who are engaged in mitigating the transaction cost of corruption. Corruption in capital-abundant countries reinforces the factor endowment bias and therefore should promote trade. For countries with similar factor endowments, relatively corrupt economy will export capitalintensive goods. We show that corruption does not necessarily reduce global volume of trade. Relatively capital-abundant country will be worse off with increasing degree of corruption at home and abroad, whereas the labor-abundant country, once engaged in trade may gain from corruption.
\end{abstract}

Keywords: Corruption, International Trade, Factor-intensity, General equilibrium JEL CL. No: 017, F1, D5

Address of corresponding author :

Biswajit Mandal

Department of Economics \& politics

Visva-Bharati University

Shantiniketan, India

731235

Telephone: (+91) 03463262751-56 Extn. 405/ Mobile: (+91) 09434155062

E-mail: biswajiteco@gmail.com 


\section{Introduction}

This paper attempts to restructure the neo-classical theory of international trade in order to find a link between corruption and comparative advantage. Such a link in turn also leads to an interesting relationship between corruption and volume of trade. We argue that corruption in labor-abundant countries will counter the factor endowment bias and will reduce the volume of world trade. If a relatively capital abundant country exhibits greater degree of corruption, trade will in fact get a boost. Equal degrees of corruption in labor abundant and capital abundant countries will not affect the volume of trade.

In the beginning, corruption was viewed as "grease in the wheels of commerce and trade" [Leff (1964), Huntington (1968)]. Some economists argued that corruption actually acts as signals for firms' competitive efficiency. But grease theory has lost much of its sheen as more and more evidence come to light showing that corruption is in fact like "sand" than "grease". Kaufman and Wei (1999) tested the grease theory, empirically, but found no support in its favour. Subsequently, corruption has been regarded as harmful for trade, in particular and economic development, in general. In most of the cases corruption leads to an increase in transaction cost [OECD (2001)] mainly through the problem of crossborder contract enforcement and naturally affects the volume of trade. Such arguments have been nicely elaborated and related papers have been surveyed in Anderson (2000). Anderson and Marcouiller (2002) provide some evidence for the theory of corruption as an extra cost. They analyze insecurity in international trade related transactions and show that if the Latin American countries were as transparent as the countries of European Union, Latin American imports would have increased by 30\%. This hypothesis is further tested in Jansen and Nordas (2004). They learn that better control of corruption is highly significantly associated with an increase in trade volume. It seems by and large that the detrimental effects of corruption on trade are unambiguously accepted in recent times. Very recently de Jong and Udo (2006) provide new evidence reconfirming the hypothesis. Their paper has shown that nature of corruption has a significant role to play on trade flows. Trade is reduced the most if corruption is of chaotic type or arbitrary in nature. In this context Wei (1997) and Lavalle (2006) are also interesting papers where it 
is shown that corruption cuts back imports by the developing nations. ${ }^{1}$ In a well known paper Trefler (1995) convincingly demonstrates the case that the volume of world trade is much less than what is predicted by HOSV paradigm.

Hence, it is possible that some of the missing trade is due to institutional complexities involved in international trade with the less governed and less transparent economies. This hypothesis is repeatedly tested over the last few years. However, there is no such theoretical General Equilibrium model which tries to incorporate corruption in the neoclassical framework and explains the missing trade mystery. In this paper we seek to fillup this caveat.

In this paper we take a slightly different theoretical view of the problem. Usually corruption enters into the trade analysis in form of transaction costs when bribe is taken by government officials in the borders ${ }^{2}$. And it is easy to understand that if contracts are relatively difficult to enforce across borders than internally, volume of trade will suffer. Suppose that this is not the case, such that relative costs of enforcement are the same internally or externally. In that case there is no special reason why international trade will suffer relative to the internal trade. However, if the traded sectors are affected more by corruption than the non-traded sector or if the exportable production is affected more than the import-competing good, trade will suffer. We abstract from all such examples of differential effect of corruption and focus on the neutral impact of corruption on two traded goods in a standard neo- classical model. This should be noted as a very natural extension of the standard general equilibrium trade theory. If a country, otherwise characterized by the attributes of a neo-classical world, is affected by corruption which eats away the output in each sector without any relative bias, will that affect the degree of comparative advantage and volume of trade?

Corruption in our framework diverts labor from productive to corruptive activities. This clue is taken from Bhagwati (1982) and Shleifer and Vishny (1993). Corruption is viewed in Bhagwati (1982) as DUP activity as many people engaged in corruption essentially avail of the arbitrage opportunities [Wei (1997)], acting as middlemen and 
intermediaries. Such diversion of human talent can be quite costly for the society and thus is related to the ideas of Shleifer and Vishny (1993). If relatively labor-abundant countries are those affected by corruption, an undeniable empirical fact given whatever data we have on inter-country measures of corruption [Mauro (1995), Lavalle (2006) etc.] the volume of world trade will shrink. We argue why corruption should affect comparative advantage and volume of trade simultaneously. It is beyond the notion of insecurity of transactions involving international trade or relative damage caused by corruption to the traded sectors. According the arguments developed in the paper, corruption in capital-abundant countries should promote trade. If in reality we do not observe much corruption in relatively capital abundant nations and we experience more of this in the labor-abundant countries, then our framework will predict lower volume of world trade.

Our argument is drawn from a reasonable assumption that economic agents often have to comply with the undesired forces of regulation, intervention, rent-seeking and corruption. Such activities lead to the emergence of a sector represented by a group of people which takes care of such institutional hazards. Typically this is a labor-intensive sector. Greater is institutional deficiency, bigger is the chunk of people who are there to avail of the arbitrage opportunities, be it in the tax-office or at customs. These are the people who negotiate for political / bureaucratic special favours, arrange to jump the "queue" and engage in many other intermediations. ${ }^{3}$ The transaction costs due to corruption are essentially spending to sustain this non-traded sector. Even without explicit taxes, tiding over regulatory complexities implies employing people who will take care of the institutional problems. This is typically a labor-intensive sector and in our paper it employs only labor. The lost value of output in each sector goes towards paying the wage bill in this non-traded sector. If the entire workforce absorbed in the non-traded sector would have been unemployed had there been no such sector, it would not have mattered much for the traded sectors. But this may not be the case. Such highly labor-intensive non-traded sector draws resources away from the labor intensive component of the traded sector, strengthening the capital intensive component via the Rybczynski effect, thus affecting the extent of comparative advantage and volume of trade. We assume zero 
international trading costs associated with corruption, so that the adverse impact, if any, on the volume of trade is generated through restricting the natural endowment bias. We also assume away any intersectoral asymmetry involving the impact of corruption.

The arrangement of the paper is as follows. Introduction is followed by the benchmark model in section 2. In section 3 we check the implication of labor mobility and immobility in the benchmark model. Section 4 deals with the impact of liberalization policy in a corruption-ridden economy. Section 5 introduces the government sector explicitly and generalizes the results derived in the benchmark model. The last section concludes. However, the mathematical details and proofs of propositions are relegated to Appendix.

\section{Section 2.1}

\section{The Benchmark model.}

With this backdrop let us consider a world economy consisting of two economies: a home and a foreign economy. The variables of the foreign economy are denoted by asterisk.Foreign economy is considered in order to compare its effective endowment with the home economy when degree of corruption changes in the home front. Our main focus is on the home economy.

Home economy is considered to be a perfectly competitive small one producing two tradeable goods, capital-intensive good $X$ and labor-intensive good $Y$. There are some people in the economy who have got the acumen to hasten process of getting authorization for producing and trading commodity $X$ and $Y$. A major portion of the total labor force is absorbed in the production of $X$ and $Y$, and others get employment due to institutional complexities involved in licensing and international trade. These institutional complexities give rise to corruption. Say $L_{z}$ laborers are used to solve these complexities. This service is not free of cost. $\alpha$ is the fraction of each good $X$ and $Y$ lost due to corruption. Therefore, $\alpha\left[P_{X} X+P_{Y} Y\right]$ represents the maximum total value of the goods that can be spent on those who are in a position to manipulate the system and recover the booty. Let $Z$ represent the sector and $L_{Z}$, the people who are exclusively engaged in such 
operations. We assume competitive market for corruption to be consistent with the otherwise standard specifications of the competitive general equilibrium model.

Foreign economy is characterized by similar variables. However, it is corruption free. Perfect competition prevails in all markets in both the countries and production functions for $X$ and $Y$ are assumed to exhibit constant returns to scale and diminishing marginal productivity.

So the structure we have, here, is the standard Jonesian [Jones (1965)] specification of $2 \times 2$ neo-classical general equilibrium model. The symbols and basic equations are in consistence with Jones (1965).

To build the system of equations, we use following notations:

$P_{i}=$ Price of $\mathrm{i}^{\text {th }}$ good, $i=X, Y$

$w=$ Return to labour

$r=$ Return to capital, $K$

$a_{i j}=$ Technological co-efficient

$\bar{K}=$ Total supply of capital

$\bar{L}=$ Total supply of labour

$L_{z}=$ Labor engaged in corruption activities

Therefore, the general equilibrium structure is like the following one:

$$
\alpha\left(P_{X} X+P_{Y} Y\right)=w L_{z}
$$

where, $\alpha \in[0,1] ; \alpha$ depends on the strength of institutional regime. A low $\alpha$ will mean low corruption/ strong institution and conversely.

Competitive price conditions are:

$$
\begin{aligned}
& w \cdot a_{L X}+r \cdot a_{K X}=P_{X}(1-\alpha) \\
& w \cdot a_{L Y}+r \cdot a_{K Y}=P_{Y}(1-\alpha)
\end{aligned}
$$

Full employment conditions are:

$$
\begin{aligned}
& a_{L X} . X+a_{L Y} . Y=\bar{L}-L_{z} \\
& a_{K X} \cdot X+a_{K Y} . Y=K
\end{aligned}
$$


Let us consider $Y$ as the numeraire commodity and set $P_{X}=P$ and $P_{Y}=1$. So, equation (1) becomes,

$\alpha(P . X+Y)=w L_{z}$

We can close the model by incorporating a homothetic demand function. This is,

$\frac{X_{D}}{Y_{D}}=f(P) ; f^{\prime}(P)<0$

Here $X_{D}$ and $Y_{D}$ signifies demand for respective commodities.

Thus the structure of the model is over. Now let us try to solve for the unknown variables. Factor endowments of labour and capital are constant at $\bar{L}, \bar{K}$. Given $\left(\alpha, P_{X}\right.$, $\left.P_{Y}\right) w$ and $r$ can be determined from equation (2) and (3). Let us start from some $L_{z}$ such that $(\bar{L}-L z)>0$. Given $(w, r)$ and hence $a_{i j} \mathrm{~s}\left(a_{i j}\right.$ is constant because of CRS $)$ and with a given value of $L_{z}$ we can solve for $X$ and $Y$ from equation (4) and (5). If we increase $L_{z}$, because of Rybczynski effect production of $X$ will expand while that of $Y$ will contract.

Note that, given $P$ with an increase in $L_{z},(P . X+Y)$ does not change due to familiar envelope property.

$(P . d X+d Y)=w \cdot d \bar{L}+r d \bar{K}=0$

Hence, LHS in (1) is constant. With $w$ determined, the RHS is linear in $L_{Z}$. Hence, we have figure -1 where $L_{Z 0}$ is determined. Now with $L_{Z 0}$ we can determine everything else in the system, in particular $X$ and $Y$ or $\left(\frac{X}{Y}\right)$. Note that sector $Z$ enters as non-traded sector along with $2 \mathrm{X} 2$ HOS system. Activity in sector $Z$ becomes "complementary" to $X$, the capita-intensive sector as $Z$ turns out to be the most labor-intensive one.

\section{Section 2.2}

\section{$\underline{A}$ rise in $\mathbf{P}$}

With a rise in $P, w$ will fall and $r$ will go up as per the Stolper-Samuelson theorem. Given $L_{Z}$, this will make the labor constraint more and capital constraint less binding. Hence due 
to Rybczynski theorem $X$ will go up and $Y$ will go down. This is clearly worked out in Jones (1965).

Now, let us look at (1). RHS in figure-1 will rotate downward since $w$ is lower and $L_{z}$ is given. Note that due to the envelope property and also for the fact that ' $\alpha$ ' is the same for both sectors, change in $(P X+Y)$ will be approximated by $d P . X$ which is greater than zero since $\mathrm{P}$ rises $\quad($ as $P d X+d Y=0)$. Hence, the LHS in figure-1 will move upward. Therefore $L_{Z}$ will increase further curtailing $Y$ and increasing $X$. Thus a rise in $P$ will raise $\left(\frac{X}{Y}\right)$, the usual supply-side response in this extended HOSV model. By using the homothetic demand function we can close the model and can determine the equilibrium value of $P$.

Our motive is to verify the impact of $\alpha$ on effective factor abundance and ultimately on autarkic price which in turn affects the volume of trade. For that purpose let us introduce a foreign economy, represented by '*', with which we compare domestic economy. Say both domestic and foreign economies are similar in technology and preference. Thus $X$ is $K$-intensive and $Y$ is $L$-intensive in both the nations. But the difference lies in factor endowments. Let the foreign economy be capital abundant. Hence,

$$
(K / L)^{*}>(K / L)
$$

For simplicity let us assume the foreign economy to be corruption free, i.e. $\alpha^{*}=0$. When both the nations are corruption free, according to HOSV prediction, for a given $P$,

$$
(X / Y)^{*}>(X / Y) \text {. }
$$

This implies, $\mathrm{P}_{\mathrm{A}}{ }^{*}<\mathrm{P}_{\mathrm{A}}$ (' $\mathrm{A}$ ' denotes autarkic situation). It is apparent that greater is the difference between $(K / L)^{*}$ and $(K / L)$ bigger will be the volume of trade or the size of so called "trade triangle".

\section{Section 2.3}

\section{Changes in ' $\alpha$ '}

Suppose there is a change in $\alpha, \alpha$ rises in the home country owing to some institutional problems. Therefore $(1-\alpha)$ falls in the home, the labor-abundant country. Note that from 
(2) and (3) given $P$ there will be symmetric response in both the price equations, $\hat{w}=\hat{r}<0\left[{ }^{‘ \wedge}\right.$ ' denotes proportional change as in Jones (1965)]. Hence, $\left(\frac{w}{r}\right)$ does not change. It is obvious, from (4) and (5), that given $L_{Z}$, nothing would change.

Now in (1) LHS has increased and RHS has fallen. Therefore, $L_{z}$ must increase lowering $Y$ and increasing $X$. But as $\alpha$ increases more payment goes to corruption sector thereby reducing the value of total production of $X$ and $Y$. Since a part of total endowment is now employed in unproductive corrupt sector $(P X+Y)$ will definitely fall. Invalidity of Envelope condition in this case does not mean a welfare loss because nothing is lost from the economy. Reduced value of $X$ and $Y$ production goes to the corrupt sector as their labor payment. This apparent loss is very much within the economy. This is what we say productivity effect beyond the envelope property. So, again from (1) LHS has fallen implying $L_{z}$ has to fall to maintain the balance. Let us assume here that the fall in $(P X+Y)$ is not so much to offset the initial rise in $L_{z}$. This assumption is reasonable because if the latter effect outweighs or more than mitigates the initial effect then nobody will find it lucrative to be engaged in corruption activities. Consequently a rise in $\alpha$ will lead to an increase in $L_{z}$ and an increase in $\left(\frac{X}{Y}\right)$. This will reduce the gap between $\left(\frac{X}{Y}\right) *$ and $\left(\frac{X}{Y}\right)$ for any given $P$. The autarkic price gap $\left(P_{A}-P_{A}^{*}\right)$ will also shrink and so will be the volume of trade. This is clearly demonstrated in figure-2. Now, the degree of effective capital abundance in the labor-abundant country should be measured as $\left(\frac{K}{L-L_{z}}\right)$. Therefore $\left(\frac{K}{L}\right)<\left(\frac{K}{L-L_{z}}\right)$
$\left(\frac{K}{L}\right)<\left(\frac{K}{L-L_{z}}\right)<\left(\frac{K}{L}\right) *$

Therefore as $\alpha$ rises in a labor abundant country its effective capital abundance is strengthened. It is also to be noted that there is no presumption as to which sector is more affected by corruption with $\alpha$ being the same for both $X$ and $Y$. But as corruption is a 
labor-intensive activity, the labor-abundant country suffers in terms of the good over which it has a comparative advantage. The message is that people, who could otherwise be involved in producing $Y$, are being engaged in illegal activities. Therefore, the corruption induced bias goes against the factor-endowment bias for a relatively laborabundant country. Due to the same reason for a capital-abundant country corruption will reinforce the endowment bias. While many papers talk about how corruption can raise trading costs and hence adversely affect the volume of trade, it is not clear how corruption actually affects the pattern of comparative advantage. If corruption is a laborintensive activity, it is definitely going to compete with other labor-intensive activities. That is how an increase in $\alpha$ affects the pattern of comparative advantage and volume of trade.

So we make the following propositions.

PROPOSITION I : Labor-abundant country's endowment bias is countered by corruption bias whereas it is further strengthened in capital-abundant country. And if two countries have similar endowment trade will be determined by relative degree of corruption.

$$
\hat{P}=(-) \frac{\psi\left[(\hat{K}-\hat{L})+\lambda_{L z}(1-a) \hat{\alpha}\right]}{\sigma_{D}+\psi \lambda_{L z}[\lambda+\theta]}
$$

Proof: See appendix A for detailed mathematical proof.

PROPOSITION II : An increase in the degree of corruption in a labor-abundant economy leads to lowering its volume of trade while it enhances the trade volume of capital-abundant country.

$$
\Delta \hat{P}=(-) \frac{\psi\left[\lambda_{L z}(1-a) \Delta \hat{\alpha}\right]}{\sigma_{D}+\psi \lambda_{L z}[\lambda+\theta]}
$$

Proof: See appendix A.

So far we have not explicitly stated the welfare consequences of introducing corruption in the standard general equilibrium model. Note that in the benchmark model $\alpha$ does not affect aggregate social welfare, since no part of the output is actually lost due to corruption. Whatever is lost in production is retained as factor earnings in the $Z$ sector. 
One can easily follow the standard welfare calculas, use the envelope condition in production and prove that welfare is invariant with respect to $\alpha$. If the labor-abundant country wishes to engage in trade, corruption will restrict volume of trade and therefore the extent of the gains from trade will be affected. Higher degree of corruption in a laborabundant country will be harmful to the capital-abundant country since higher output of capital intensive good will depress world price of that good, causing a terms of trade loss for the capital-abundant country. In fact under free trade the capital-abundant economy will be worse off with increasing corruption at home and abroad. Interestingly once engaged in trade, the labor-abundant economy will actually gain from further corruption, through an improvement in the terms of trade.

In the next section we will incorporate a labor supply function to assess whether labormobility has any role to play in a corruption-ridden economy to affect the volume of trade.

\section{Section 3.1}

Without losing generality we can make following changes in the benchmark model of the preceding section.

There are two types of labor in the economy, say, $L_{I}$ and $L_{z} . L_{z}$ is different from $L_{l}$ in the sense that these people have got the acumen to hasten process of getting authorization for producing and trading commodity $X$ and $Y . L_{1}$ is absorbed in the production of $X$ and $Y$, but $L_{z}$ get employment due to institutional complexities involved in licensing and international trade. These institutional complexities give rise to corruption. $L_{z}$ laborers are used exclusively to solve these complexities. This service is not free of cost. $\alpha$ is the fraction of good $X$ and $Y$ spent for corruption purpose.

So the modified notations and the system of equations is as follows:

$w_{l}=$ Return to type-I labor, $L_{l}$

$w_{z}=$ Return to type-II labor, $L_{z}$

$L_{1}=$ Total supply of type-I labor 
$L_{z}=$ Total supply of type-II labor

$\bar{L}=$ Total supply of labor (type-I + type-II)

Therefore, equation (1) becomes:

$$
\alpha\left(P_{X} X+P_{Y} Y\right)=w_{z} L_{z}
$$

Competitive price conditions are:

$$
\begin{aligned}
& w_{1} \cdot a_{L 1 X}+r . a_{K X}=P_{X}(1-\alpha) \\
& w_{1} \cdot a_{L 1 Y}+r . a_{K Y}=P_{Y}(1-\alpha)
\end{aligned}
$$

Full employment conditions are:

$$
\begin{aligned}
& a_{L 1 X} \cdot X+a_{L 1 Y} . Y=L_{1}=\bar{L}-L_{z} \\
& a_{K X} \cdot X+a_{K Y} . Y=K
\end{aligned}
$$

Supply of labor to production and corruption sector depends on relative wages. Therefore, the labor mobility condition is:

$$
\frac{L_{1}}{L z}=g\left(\frac{w_{1}}{w_{z}}\right) ; g^{\prime}>0
$$

Homothetic demand function is as before.

\section{Section 3.2}

\section{Changes in ' $\alpha$ '}

In this section we address an important question under two different conditions. How does a change in the degree of corruption in home country affect the degree of factor abundance and hence volume of trade:

(A) when labor is perfectly mobile between production and corruption activity?

(B) when labor is absolutely immobile between production and corruption activity?

From the labor mobility condition what we get is,

$$
\hat{w}_{z}=(-) \theta \hat{P}-\frac{\hat{L}_{1}-\hat{L}_{z}}{\phi}
$$


where, $\phi$ denotes the elasticity of labor mobility function and $0 \leq \phi \leq \infty$.

CASE :A Perfect mobility of labor between production and corruption activity, $\phi=\infty$.

For a given $P$, a rise in $\alpha$ results in a decrease in $w_{1}$. Under perfect labor mobility $w_{z}=w_{1}$. Laborers will move from production activity to corruption sector. Thus $L_{z}$ rises and $L_{1}$ falls because $L_{1}+L_{z}=\bar{L}$. The subsequent arguments are same as in section 2.3.

Basically, in a corruption-ridden economy volume of trade depends on effective factor abundance. Effective factor abundance is measured by the ratio of factors actually employed in the production of traded goods. In the domestic economy effective capital abundance is denoted by $\frac{K}{L-L_{z}}$, because though $L_{z}$ is included in total workforce they are being used to produce only non-traded corruption commodity (services). So,

$$
\left(\frac{K}{L}\right)<\left(\frac{K}{L-L_{z}}\right)<\left(\frac{K}{L}\right) *
$$

Here, relative endowment difference of home country with that of foreign country is getting smaller since $L_{z}$ rises as a result of an increase in $\alpha$. Essentially, corruption, $\alpha$ is playing a pivotal role in changing endowment bias of the domestic labor-abundant economy. The important parameter through which change in production and price takes place is $L_{z} . L_{z}$ is linking up the production sector with corruption. Hence, corruption induces bias against natural endowment bias of labor-abundant economy because, corruption requires only labor who could otherwise be employed in labor-intensive $Y$ production.

So, as the degree of corruption increases, a labor-abundant economy gradually loses its comparative advantage over labor-intensive commodity since it becomes less and less effective labor-abundant. For converse reasoning an increase in corruption strengthens the endowment bias of a capital-abundant country and increases the degree of its comparative advantage over capital-intensive commodity. 
We make the following proposition based on this intuitive analysis.

PROPOSITION III : An increase in the degree of corruption in a labor-abundant economy leads to lowering its volume of trade if labor can freely move between production and corruption activity.

$$
\Delta \hat{P}=(-) \frac{\psi\left[\lambda_{L z}(1-a) \Delta \hat{\alpha}\right]}{\sigma_{D}+\psi \lambda_{L z}[\lambda+\theta]}
$$

\section{Proof: See appendix B for detailed mathematical proof.}

CASE :B Perfect immobility of labor between production and corruption activity, $\phi=0$.

A rise in $\alpha$ leads to a symmetric change in $w_{1}$ and $r$ in equation (14) and (15) for a given $P$. In addition, $\hat{w}_{1}=\hat{r}<0$. But the possibility of change in $L_{z}$ is ruled out here, as we consider zero mobility of labor. $L_{z}$ remains constant. This can only happen if the skill required for production and corruption activities are distinctly different. Consequently, production of $X$ and $Y$ remains undisturbed thusby keeping $P_{A}$ unchanged. This means effective factor abundance of a corruption-ridden labor-abundant economy does not get affected and so is the volume of trade. Essentially, zero elasticity of labor mobility function insulates the production sector from any shock stemming from corruption.

However, from equation (13) LHS has risen as $\alpha$ has increased and there is no change in $P_{X}, P_{Y}, X$ and $Y$. In the RHS of equation (13) any change in $L_{z}$ is constrained by labor immobility. So to bring back the balance $w_{z}$ has to rise. The argument is very simple. Same numbers of people are now working more as degree of corruption rises. So, in a sense their marginal productivity is on a rise and that is why they are paid a higher return compared to the situation when degree of corruption was less.

The following proposition is immediate

PROPOSITION IV : An increase in the degree of corruption in a labor abundant country can't affect the volume of trade if laborers are not allowed to move between production and corruption activity.

$$
\Delta \hat{P}=0
$$


Proof: See appendix B for detailed mathematical calculation.

Welfare implication of this analysis is just like the discussion of benchmark model.

\section{Section 4.1}

In this section we consider the same economy but its import competing sector is assumed to be protected by a tariff even in the presence of corruption. For the time being let us abstract ourselves from welfare implication of a change in consumption and tariff revenue collection due to a change in tariff rate. In our framework $X$ is the import competing good. This is justifiable for a labor-abundant developing economy. Except equation (2) of the benchmark model all other equations will remain as it is. Equation (2) becomes

$w \cdot a_{L X}+r \cdot a_{K X}=P_{X}(1-\alpha)=\left\{P_{X} *(1+t)\right\}(1-\alpha)$

Here, ' $t$ ' is the rate of advalorem tariff. Note that domestic producer can not charge a price higher than the tariff inclusive price of imports, $\left\{P_{X} *(1+t)\right\}$.

\section{Section 4.2}

\section{Economic Liberalization}

Initiation of economic liberalization policy means a cut in existing tariff rate leading to a fall in $P_{X}\left[=P_{X} *(1+t)\right]$. Subsequently $r$ falls and $w$ rises due to Stolper-Samuelson theorem and $X$ production decreases and that of $Y$ rises which is usual supply side response. Since $w$ rises more labor will flow out of existing corruption sector and prefer to join production activity. Therefore $L_{z}$ falls curtailing the production of $X$ and raising the production of $Y$ further due to Rybczynski effect. As a consequence of this autarkic price ratio $P_{A}$ rises in domestic economy and results in an increase in volume of trade. This is the conventional wisdom and it is valid even in presence of corruption. But for a capital-abundant country the same liberalization policy provides us with contrasting result. There economic liberalization leads to a fall in $L_{z}$ and consequently lowering the 
volume of trade. So a same policy may come up with two different results in two different situations.

$$
\Delta \hat{P}=(-) \frac{\psi\left[\lambda_{L z} \Delta \hat{L}_{z}\right]}{\sigma_{D}}
$$

For detailed calculation see appendix $C$

Interestingly we may think of a situation where $\alpha$ may not be independent of ' $t$ '. In fact it is more justifiable to assume that $\alpha=\alpha(t)$ where $\alpha^{\prime}(t)>0$ since corruption results from the power that bureaucrats enjoy and protection creates an ambience of giving and taking some kind of undue advantage. Perhaps that why we found a negative relationship between economic reform and corruption in some countries [Basu and David (1996), Broadman and Recanatini (2001), Treisman (2000) and Tavares (2005)].

Under this circumstance our modified price equations would be:

$$
\begin{aligned}
& w \cdot a_{L X}+r \cdot a_{K X}=P_{X}(1-\alpha)=\left\{P_{X} *(1+t)\right\}\{1-\alpha(t)\} \\
& w \cdot a_{L Y}+r \cdot a_{K Y}=P_{Y}\{1-\alpha(t)\}
\end{aligned}
$$

As a consequences of a reduction in tariff rate following economic liberalization will lead to a fall in $w$ unambiguously. But there may be a rise or fall in $r$ depending upon the condition that $\hat{r}>0$ iff $\frac{d \alpha(t)}{d t}<\frac{1-\alpha(t)}{1+t} \frac{\theta_{L Y}}{|\theta|}$ and $\hat{r}<0$ iff $\frac{d \alpha(t)}{d t}>\frac{1-\alpha(t)}{1+t} \frac{\theta_{L Y}}{|\theta|}$. Whatever be the direction of change in $r$ as $w$ falls in production activity people will move out from productive sector and flock into the corruptive sector. Therefore $L_{z}$ rises. Hence due to Rybczynski's theorem production of labor-intensive commodity $Y$ decreases while that of $X$ increases. Subsequently, $\frac{P_{X}}{P_{Y}}$ falls and also the difference in autarkic price gap leading to a reduction in the volume of trade.

So, economic reform leads to a decline in volume of trade when corruption itself is a function of degree of protection, be it tariff or subsidy. We do not get the traditional 
outcome, where dismantling of trade barriers is supposed to enhance the volume of trade. Contrarily a capital-abundant country will get the usual result due to economic reform even in presence of corruption, dependent of tariff. Whether economic liberalization will boost up the volume of trade or not that essentially depends on whether $\alpha$ is dependent or independent of tariff or trade barriers.

PROPOSITION $\boldsymbol{V}$ : Economic reform may lead to a reduction in the volume of trade in the labor-abundant country if corruption is a function of rate of protection. But the same policy will result in an in crease in volume of trade for capital-abundant contry.

For detailed calculation see appendix C

Corruption sector that exclusively uses labor is doing the trick again.

So far we assumed that corruption is exogenous and also the policy of economic liberalization. But corruption may have a relation with the volume of economic activity triggered by liberalization policy. Economic liberalization may lead to an increase in productive activities that needs help of government or bureaucracy for facilitating it. In that case economic liberalization might further trigger corruption in liberalized economy. In order to understand the situation we need to endogenise corruption.

In the next section we talk about a scenario where there is a net loss from corruption. But once engaged in trade we should have similar terms of trade effects of a rising corruption as in the benchmark model.

\section{$\underline{\text { Section } 5.1}$}

The benchmark model we have discussed so far has two major restrictions. First, $\alpha$ is exogenous. Second, corruption in this structure is simply a transfer from production to a service sector which takes care of the transaction costs. In this section, we treat $\alpha$ as a variable which depends on the size of the government or bureaucracy. $L_{g}$ denotes the size 
of the government or bureaucracy which may facilitate productive activity through the proper provisioning of public services. But at the same time regulations and complex layers of decision making may increase transaction costs and induce corruption. Thus $L_{g}$ can affect $\alpha$ either way. We start from a situation where

$$
\alpha=\alpha\left(L_{g}\right), \alpha^{\prime}>0
$$

We also assume that for $\alpha\left(L_{g}\right)$ lost in the process only $\beta \alpha\left(L_{g}\right)$ is recovered, $0<\beta<1$. Therefore, $(1-\beta) \alpha\left(L_{g}\right)$ is the cost due to corruption which cannot be recovered. $\beta \alpha\left(L_{g}\right)$ is recovered but is spent away towards paying bribe to the bureaucrat and fees to the intermediaries. The $Z$ sector's balancing condition looks as follows.

$\beta \alpha\left(L_{g}\right)[P X+Y]=\left[w+w_{b}\left(L_{z}\right)\right] L_{g}+w \cdot L_{z}, w_{b}{ }^{\prime}<0$

Note that we now have $w_{b}$ as the "rent" enjoyed by those powerful in the government to affect productive activities. One can interpret $\beta \alpha\left(L_{g}\right)[P X+Y]$ as tax revenue and bribe money. The bribe goes to pay the premium $w_{b}$ which depends on $L_{z}$. Employing greater number as of intermediaries means economizing on paying the premium.

Note that each member in the group $L_{g}$ earns $w+w_{b}$. Therefore, everyone would like a government job since it pays a premium on top of $w$. To motivate on comparative static results we assume $L_{g}$ is determined by a government quota. We have stated earlier, $L_{g}$ can negatively affect $\alpha$ when public services help reduce transaction costs. Higher $L_{g}$ may intensify the transaction cost as well. In both cases, one can justify a premium $w_{b}$. In the former case public officials are paid so that they get added incentive for helping the production process. When higher $L_{g}$ increases $\alpha$, bribe needs to be paid for avoiding harassment.

Given $L_{g}$, one can determine all the variables. We proceed exactly in the same fashion as in the benchmark model. Let us start from a given $P$, we can determine $w, r$ from the competitive cost conditions. Then equation (25) determines $L_{z}$. Note that given $P$, 
$(P X+Y)$ is independent of $L_{z}$. Then given $L_{z}$, we can solve for $X$ and $Y$. Now as $P$ increases, given $L_{g}$ and $L_{z}, X$ must increase and $Y$ must go down.

From (25) by differentiating w.r.t. $P$ and using the envelope condition we get,

$$
\frac{d L_{z}}{d P}=\left[\beta \alpha\left(L_{g}\right) \cdot X-\frac{d w}{d P}\left(L_{z}+L_{g}\right)\right] / \Delta
$$

Note that, due to Stolper-Samuelson argument, $d w / d P<0$ and $\Delta=w+L_{g} . w_{b}{ }^{\prime}\left(L_{z}\right)>0$ implies that the RHS in (25) is increasing in $L_{z .} \Delta$ guarantees the stability of equilibrium $L_{z \text { z. As }} P$ goes up and consequently $L_{z,} X$ goes up further and $Y$ shrinks due to Rybczynski argument. Thus relative supply of $X$ increases with $P$ and we close the system with homothetic demand to find out the equilibrium relative price in autarky.

\section{Section 5.2}

Now we need to chalk out how $L_{z}$ may get affected in order to understand the role of government bureaucracy in enhancing the volume of trade when corruption is being endogenous. Higher costs incurred due to corruption or regulatory control are reflected through a higher $\beta$ or $L_{g}$. In case, greater $L_{g}$ implies positive pro-active influence on productive activity, $\alpha\left(L_{g}\right)$ should be decreasing in $L_{g}$. But the possibility is always there that regulations and complex layers of decision making may increase transaction costs and induce corruption, $\alpha\left(L_{g}\right)$ should be increasing in $L_{g}$.

Let us derive the effect of a change in $\beta$ and $L_{g}$ on $L_{z}$ from (25).

Differentiating (25) with respect to $\beta$ and $L_{g}$ for a given $P$ and using envelope condition we get,

$\frac{d L_{z}}{d \beta}=\frac{\left[\alpha\left(L_{g}\right)(P . X+Y)\right]}{\Delta}>0$

and 
$\frac{d L_{z}}{d L_{g}}=\frac{\left[\beta \alpha^{\prime}\left(L_{g}\right)(P . X+Y)-\left[w+w_{b}\left(L_{z}\right)\right]-\left(L_{z}+L_{g}\right) \frac{d w}{d L_{g}}\right]}{\Delta}$

$\frac{d L_{z}}{d L_{g}}>0$ or $\frac{d L_{z}}{d L_{g}}<0$

We discuss both the possibilities now. When $L_{g}$ increases, $\alpha$ can go up or down. Suppose, $\alpha$ goes down $\alpha^{\prime}<0$. The RHS in (25) will increase for a given $w$, reducing $L_{z}$ in order to balance both sides. But with more productive activity factor returns improve. Therefore as w increases, $L_{z}$ needs to fall further. This is captured in (28). If $\alpha^{\prime}<0$, then $d w / d L_{g}>0$. Therefore the numerator in (28) is negative implying $d L_{z} / d L_{g}<0$. This suggests that a more productive bureaucracy must imply fewer people earning as intermediaries.

If $\alpha^{\prime}>0, d w / d L_{g}<0$. But still $d L_{z} / d L_{g}$ can be negative. This happens iff $\left|\left(w+w_{b}\right)\right|>\left|\left\{\beta \alpha^{\prime}\left(L_{g}\right)(P . X+Y)-\left(L_{z}+L_{g}\right) \frac{d w}{d L g}\right\}\right|$. Because an increase in $L_{g}$, ceteris paribus, increases the cost of sustaining bureaucracy. A sufficiently strong $\alpha^{\prime}$ and/ or $d w / d L_{g}$ will make $d L_{z} / d L_{g}>0$.

Therefore, we can write down the following proposition.

\section{PROPOSITION VI:}

a) Higher $\beta$ will increase $L_{z}$ for a given $P$ and $L_{g}$

b) Higher $L_{g}$ will reduce $L_{z}$ for a given $P$ and $\beta$ provided $\alpha^{\prime}<0$

c) Higher $L_{g}$ may increase $L_{z}$ for a given $P$ and $\beta$ provided $\alpha^{\prime}>0$

Proof: see the discussion above and see Appendix D for mathematical details.

Note that whenever both $L_{g}$ and $L_{z}$ go up for a given $P, X$ must go up and $Y$ should decline. Therefore, for a given $P$, relative supply of $X$ increases driving down the autarkic relative price. Thus a relatively corrupt economy will have an export bias in favor of the capital intensive good. Hence as we have shown in the benchamark model, if a labor abundant economy has a greater $\beta$ or $L_{g}$, its autarkic relative price of the labor intensive 
good will be higher compared to no-corruption case. Hence, corruption bias will go against the factor-endowment bias curtailing the volume of trade.

If $\alpha^{\prime}<0$ and $d w / d L_{g}$ are strong enough $L_{z}$ will fall when $L_{g}$ goes up. In this case, there is a possibility that when $L_{g}$ goes up, $\left(L_{z}+L_{g}\right)$ may go down increasing relative supply of $Y$ and hence increasing $P$. This is a case where more productive bureaucracy promotes export in labor-intensive good and increases the volume of trade.

It is possible that as $L_{g}$ goes beyond a level, $\alpha$ responds positively to increasing $L_{g}$. Therefore, the relative price of the labor intensive good may go down following the initial rise in $L_{g}$ and then will go up eventually. For a relatively labor abundant economy, a relatively productive bureaucracy will promote trade, but eventually trade gets restricted with bulging bureaucracy. So we can have a critical value of $L_{g}$ upto which bueaucracy is not bad, at all, for a labor-abundant economy. For this value of $L_{g}$ following condition will hold true,

$$
\left|\left(w+w_{b}\right)\right|=\left|\left\{\beta \alpha^{\prime}\left(L_{g}\right)(P . X+Y)-\left(L_{z}+L_{g}\right) \frac{d w}{d L_{g}}\right\}\right|
$$

Figure 3 captures the possibility. $D$ denotes the difference between the world and local (autarkic) relative price of the labor intensive good. Let $\bar{L}_{g}$ denote that level of $L_{g}$ which borderlines the cases when bureaucracy starts having an unproductive influence on the autarkic production bundle.

Increase in $D$ represents greater volume of trade. Hence volume of trade for the laborabundant economy increases with $L_{g}$ initially and then drops.

The analysis in this section corroborates our earlier claim with a constant $\alpha$. Corruption led transaction costs either in terms of a higher $\beta$ or rising $L_{g}$ will generally lead to a higher $L_{z}$. This will work against the factor-endowment bias in a typical labor-abundant country, restricting the volume of trade. For a capital-abundant country the result will be exactly opposite. 
One important characteristic of trade between two countries, identical in every respect except differing in terms of $L_{g}$ and $\beta$ is that under free trade factor prices do not equalize. $\beta$ or $L_{g}$ acts as a productivity parameter and under free trade both $w$ and $r$ are likely to be lower in a country with higher $\beta$ and/or $L_{g}$. As opportunity for international factor mobility arises, both labor and capital will be inclined to flow out of the more corrupt economy. Also to be noted is the fact that as a labor-abundant country engages in trade, the relative price of the labor-intensive good increases, leading to a lower $L_{z}$ and a smaller size of the $Z$ sector or a cut back in activities involving the corrupt segment of the economy. But at the same time the earning of a typical bureaucrat increases with an increase in $w$ as well as an increase in $w_{b}\left(L_{z}\right)$. However, as long as the elasticity of $w_{b}$ with respect to $L_{z}$ is not too strong, one could expect a tilt of wage distribution in favor of the non-bureaucrats.

\section{Section 6}

\section{Conclusion}

The purpose of this paper is to model corruption as a labor-intensive activity within a simple general equilibrium framework and then explain the relationship between international trade and corruption. We argue that the standard HOSV framework provides some insights regarding such a relationship. Corruption is a labor-intensive activity. Hence, as more labor is attracted to this sector, labor-intensive traded good suffers, so does the volume of trade for the labor-abundant economy. This shows that even if corruption does not directly affect trading costs, we can still have lower volume of trade. The scenario in the paper is one where the labor-abundant economy suffers from corruption, but not the capital -abundant one. A corrupt capital-abundant nation is likely to trade more than under the usual "non-corruption" case. Thus corruption leading to greater volume of trade is a distinct possibility. Moreover, our results indicate that there may be a case when in a labor-abundant economy exports are really capital intensive and a large chunk of the labor force is absorbed in the extra-legal non-traded activities. Possibility of labor mobility is very crucial in affecting volume of trade in a corrupt- 
economy. Labor immobility insulates the production sector from any shock stemming from corruption. Moreover if import-competing sector of a labor-abundant country is protected by a tariff in a corruption-ridden economy a policy of economic liberalization helps increasing the volume of trade while the same policy results in a contraction in volume of trade for corrupt capital-abundant nation.

If corruption leads to the relative abundance of capital intensive good it hurts welfare of a capital-abundant economy. Therefore, such a nation will always despise corruption, a reason grounded in economic reality without much of a moral connotation. Once engaged in trade the labor-abundant country may not mind being more corrupt. Since corruption leads to improvement of its terms of trade. In the extended model the welfare loss due to greater corruption has to be weighed against the terms of trade gain due to greater production of capital intensive good. We may also have a critical level of government bureaucracy for which it is optimum in raising the volume of trade. An excessive bureaucracy itself may instigate more people to be engaged in corruption activities. 


\section{Appendix A}

Differentiating and manipulating equation (2) and (3) we get,

$$
\begin{aligned}
& \hat{w} \cdot \theta_{L X}+\hat{r} \cdot \theta_{K X}=\hat{P}_{X}(1-\alpha) \\
& \hat{w} \cdot \theta_{L Y}+\hat{r} \cdot \theta_{K Y}=\hat{P}_{Y}(1-\alpha)
\end{aligned}
$$

Where, $\theta_{L X} \Rightarrow$ value share of $L$ in $X$

$$
\begin{aligned}
& \theta_{K X} \Rightarrow \text { value share of } K \text { in } X \\
& \theta_{L Y} \Rightarrow \text { value share of } L \text { in } Y \\
& \theta_{K Y} \Rightarrow \text { value share of } K \text { in } Y
\end{aligned}
$$

Matrix representation of the previous equations is,

$$
\left(\begin{array}{ll}
\theta_{L X} & \theta_{K X} \\
\theta_{L Y} & \theta_{K Y}
\end{array}\right) \quad\left(\begin{array}{l}
\hat{w} \\
\hat{r}
\end{array}\right)=\left(\begin{array}{c}
\hat{P}_{X}(1-\alpha) \\
\hat{P}_{Y}(1-\alpha)
\end{array}\right)
$$

So, we have

$$
\hat{w}(-|\theta|)+\hat{r}|\theta|=(1-\alpha)\left(\hat{P}_{X}-\hat{P}_{Y}\right)
$$

consider $Y$ as the numeraire commodity and set $P_{X}=P$ and $P_{Y}=1$.

Therefore, $\quad(\hat{r}-\hat{w})=\frac{1-\alpha}{|\theta|} \hat{P}$

Where, $\quad|\theta|=\left(\begin{array}{ll}\theta_{L Y} & \theta_{K Y} \\ \theta_{L X} & \theta_{K X}\end{array}\right)=\left(\theta_{K X}-\theta_{K Y}\right)=\left(\theta_{L Y}-\theta_{L X}\right)$

Here, $|\theta|>0$ because commodity $X$ is $K$-intensive.

Solving for $\hat{w}$ we get,

$$
\hat{w}=\hat{P}(1-\alpha)\left[1-\frac{\theta_{K X}}{|\theta|}\right] \quad \text { where, }\left(1-\frac{\theta_{K X}}{|\theta|}\right)<0
$$

Therefore, $\hat{w}=-\theta \hat{P}$

$$
\text { where, }(-\theta)=(1-\alpha)\left[1-\frac{\theta_{K X}}{|\theta|}\right]
$$

here, $\theta>0$ because of Stolper-Samuelson theorem. 
Differentiating equation (4) and (5) and manipulating them one gets,

$$
(\hat{X}-\hat{Y})=\psi(\hat{K}-\hat{L})+\psi \hat{L}_{z} \lambda_{L z}
$$

here, $\psi>0$, due to Rybczynski's effect.

From equation (6)

$$
(1-a) \hat{\alpha}+\hat{V}=-\theta \hat{P}+\hat{L}_{z}
$$

where, $\quad 0 \leq a<1$

Here, “ $\boldsymbol{a}$ ” captures the effect that as $\alpha$ increases more payment goes to corrupt sector. If we start from no-corruption level, $a=0$. Here, $\hat{V}=\lambda \hat{P}$ and $\lambda$ is the share of $X$ in national income.

Therefore, $\quad \hat{L}_{z}=(1-a) \hat{\alpha}+\hat{P}(\lambda+\theta)$

From homothetic demand function what we have,

$$
\hat{X}_{D}-\hat{Y}_{D}=-\sigma_{D} \hat{P}
$$

From equation (A.3), (A.5) and (A.6) we get,

$$
\hat{P}=(-) \frac{\psi\left[(\hat{K}-\hat{L})+\lambda_{L z}(1-a) \hat{\alpha}\right]}{\sigma_{D}+\psi \lambda_{L z}[\lambda+\theta]}
$$

Hence proposition I is proved.

So the difference in autarkic price level relative to benchmark no-corruption level is given by,

$$
\Delta \hat{P}=(-) \frac{\psi\left[\lambda_{L z}(1-a) \Delta \hat{\alpha}\right]}{\sigma_{D}+\psi \lambda_{L z}[\lambda+\theta]}
$$

Hence proposition II is proved. 


\section{APPENDIX B}

Differentiating and manipulating price equations we get,

$$
\begin{aligned}
& \hat{w}_{1} \cdot \theta_{L 1 X}+\hat{r} \cdot \theta_{K X}=\hat{P}_{X}(1-\alpha) \\
& \hat{w}_{1} \cdot \theta_{L 1 Y}+\hat{r} \cdot \theta_{K Y}=\hat{P}_{Y}(1-\alpha)
\end{aligned}
$$

Where, $\theta_{L 1 X} \Rightarrow$ value share of $L_{l}$ in $X$

$$
\begin{aligned}
& \theta_{K X} \Rightarrow \text { value share of } K \text { in } X \\
& \theta_{L 1 Y} \Rightarrow \text { value share of } L_{1} \text { in } Y \\
& \theta_{K Y} \Rightarrow \text { value share of } K \text { in } Y
\end{aligned}
$$

Matrix representation of the previous equations is,

$$
\left(\begin{array}{ll}
\theta_{L 1 X} & \theta_{K X} \\
\theta_{L 1 Y} & \theta_{K Y}
\end{array}\right) \quad\left(\begin{array}{l}
\hat{w}_{1} \\
\hat{r}
\end{array}\right)=\left(\begin{array}{l}
\hat{P}_{X}(1-\alpha) \\
\hat{P}_{Y}(1-\alpha)
\end{array}\right)
$$

So, we have

$$
\hat{\mathcal{W}}_{1}(-|\theta|)+\hat{r}|\theta|=(1-\alpha)\left(\hat{P}_{X}-\hat{P}_{Y}\right) ;
$$

consider $Y$ as the numeraire commodity and set $P_{X}=P$ and $P_{Y}=1$.

Therefore, $\quad\left(\hat{r}-\hat{w}_{1}\right)=\frac{1-\alpha}{|\theta|} \hat{P}$

Where, $\quad|\theta|=\left(\begin{array}{ll}\theta_{L 1 Y} & \theta_{K Y} \\ \theta_{L 1 X} & \theta_{K X}\end{array}\right)=\left(\theta_{K X}-\theta_{K Y}\right)=\left(\theta_{L 1 Y}-\theta_{L 1 X}\right)$

Here, $|\theta|>0$ because commodity $X$ is $K$-intensive.

Solving for $\hat{w}_{1}$ we get,

$$
\hat{w}_{1}=\hat{P}(1-\alpha)\left[1-\frac{\theta_{K X}}{|\theta|}\right] \quad \text { where, }\left(1-\frac{\theta_{K X}}{|\theta|}\right)<0
$$

Therefore, $\hat{w}_{1}=(-\theta) \hat{P}$ 


$$
\text { where, }(-\theta)=(1-\alpha)\left[1-\frac{\theta_{K X}}{|\theta|}\right]
$$

here, $\theta>0$ because of Stolper-Samuelson theorem.

Differentiating quantity equations and manipulating them one gets,

$$
(\hat{X}-\hat{Y})=\psi(\hat{K}-\hat{L})+\psi \hat{L}_{z} \lambda_{L z}
$$

here, $\psi>0$, due to Rybczynski's effect.

Differentiating equation (13)

$$
(1-a) \hat{\alpha}+\hat{V}=\hat{w}_{z}+\hat{L}_{z}
$$

where, $\quad 0 \leq a<1$

Here, “ $a$ " captures the effect that as $\alpha$ increases more payment goes to corrupt sector. If we start from no-corruption level, $a=0$. Here, $\hat{V}=\lambda \hat{P} \quad$ and $\lambda$ is the share of $X$ in national income.

Therefore, $\quad \hat{L}_{z}=(1-a) \hat{\alpha}+\lambda \hat{P}-\hat{w}_{z}$

From homothetic demand function what we have,

$$
\hat{X}_{D}-\hat{Y}_{D}=-\sigma_{D} \hat{P}
$$

From labor mobility function we essentially get,

$$
\Phi=\frac{\hat{L}_{1}-\hat{L}_{z}}{\hat{w}_{1}-\hat{w}_{z}}, \text { where } \phi \text { is the elasticity of labor mobility function and } 0 \leq \Phi \leq \infty .
$$

So, $\quad \hat{w}_{z}=\hat{w}_{1}-\frac{\hat{L}_{1}-\hat{L}_{z}}{\phi}$

Therefore, $\quad \hat{w}_{z}=(-\theta) \hat{P}-\frac{\hat{L}_{1}-\hat{L}_{z}}{\phi}$

Substituting the value of $\hat{w}_{z}$ in (B.5) one gets,

$$
\begin{gathered}
\hat{L}_{z}=(1-a) \hat{\alpha}+\lambda \hat{P}+\theta \hat{P}+\frac{\hat{L}_{1}-\hat{L}_{z}}{\phi} \\
\text { Or, } \hat{L}_{z}=\frac{1}{\left(1+\frac{1}{\phi}\right)}\left[(1-a) \hat{\alpha}+\frac{\hat{L}_{1}}{\phi}+\lambda \hat{P}+\theta \hat{P}\right]
\end{gathered}
$$


From equation (B.3), (B.6) and (B.9) we get,

$$
-\sigma_{D} \hat{P}=(\hat{K}-\hat{L}) \psi+\frac{\psi \lambda_{L z}}{1+\frac{1}{\phi}}(1-a) \hat{\alpha}+\frac{\psi \lambda_{L z}}{1+\frac{1}{\phi}} \frac{\hat{L}_{1}}{\phi}+\lambda \hat{P} \frac{\psi \lambda_{L z}}{1+\frac{1}{\phi}}+\frac{\psi \lambda_{L z}}{1+\frac{1}{\phi}} \theta \hat{P}
$$

Rearranging and manipulating the above equation one can get the value of $\hat{P}$. Therefore,

$$
\hat{P}=(-) \frac{\psi\left[\hat{K}-\hat{L}_{1}\left(\lambda_{L 1 X}+\lambda_{L 1 Y}\right)-\hat{L}_{z} \lambda_{L z}+\frac{\lambda_{L z}}{1+\frac{1}{\phi}}(1-a) \hat{\alpha}+\frac{\lambda_{L z}}{1+\frac{1}{\phi}} \frac{\hat{L}_{1}}{\phi}\right]}{\sigma_{D}+\frac{\psi \lambda_{L z}}{1+\frac{1}{\phi}}[\lambda+\theta]}
$$

where, $\lambda_{L 1 Y}=$ share of labor engaged in $Y$ production

$\lambda_{L 1 X}=$ share of labor engaged in $X$ production

$\lambda_{L z}=$ share of labor engaged in corruption acitivity

CASE :A Perfect mobility of labor between production and corruption activity, $\phi=\infty$.

$$
\hat{P}=(-) \frac{\psi\left[\hat{K}-\hat{L}_{1}\left(\lambda_{L 1 X}+\lambda_{L 1 Y}\right)-\hat{L}_{z} \lambda_{L z}+(1-a) \hat{\alpha} \lambda_{L z}\right]}{\sigma_{D}+\psi \lambda_{L z}[\lambda+\theta]}
$$

if there is no corruption,

$$
\hat{P}=(-) \frac{\psi\left[\hat{K}-\hat{L}_{1}\left(\lambda_{L 1 X}+\lambda_{L 1 Y}\right)-\hat{L}_{z} \lambda_{L z}\right]}{\sigma_{D}+\psi \lambda_{L z}[\lambda+\theta]}
$$

So, the difference autarkic price level relative to benchmark no-corruption level will be measured by,

$$
\Delta \hat{P}=(-) \frac{\psi\left[\lambda_{L z}(1-a) \Delta \hat{\alpha}\right]}{\sigma_{D}+\psi \lambda_{L z}[\lambda+\theta]}
$$

- Hence Proposition-III is proved.

CASE :B Perfect immobility of labor between production and corruption activity, $\phi=0$. 


$$
\hat{P}=-\frac{\psi\left[\hat{K}-\hat{L}_{1}\left(\lambda_{L 1 X}+\lambda_{L 1 Y}\right)-\hat{L}_{z} \lambda_{L z}\right]}{\sigma_{D}}
$$

Benchmark no-corruption level of $\hat{P}$ is

$$
\hat{P}=-\frac{\psi\left[\hat{K}-\hat{L}_{1}\left(\lambda_{L 1 X}+\lambda_{L 1 Y}\right)-\hat{L}_{z} \lambda_{L z}\right]}{\sigma_{D}}
$$

So, the difference autarkic price level relative to benchmark no-corruption level is given by,

$$
\Delta \hat{P}=0
$$

- Hence Proposition-IV is proved

\section{APPENDIX C}

Differentiating equation (6) w.r.t. $P$ one gets,

$\frac{d L_{z}}{d P}=\frac{\alpha \cdot X-\frac{d w}{d P} L_{z}}{w}$

here $\frac{d w}{d P}<0$ (from Stolper-Samuelson theorem)

so, $\frac{d L_{z}}{d P}>0$

Using homothetic demand function, equation (A.3) and comparing it with preliberalization phase we get the difference in autarkic price level as,

$$
\Delta \hat{P}=(-) \frac{\psi\left[\lambda_{L z} \Delta \hat{L}_{z}\right]}{\sigma_{D}}
$$

Thus the explanation of Section $\mathbf{4 . 2}$ is proved.

Differentiating and manipulating equation $(2 \mathrm{~A})$ and $(3 \mathrm{~A})$ one gets, 


$$
\begin{aligned}
& \hat{w} \cdot \theta_{L X}+\hat{r} \cdot \theta_{K X}=\frac{1-\alpha(t)}{1+t} d t-d \alpha(t) \\
& \hat{w} \cdot \theta_{L Y}+\hat{r} \cdot \theta_{K Y}=-d \alpha(t)
\end{aligned}
$$

Solving for $\hat{w}$ and $\hat{r}$ we get,

$$
\hat{w}=\frac{\frac{1-\alpha(t)}{1+t} d t \theta_{K Y}-d \alpha(t) \theta_{K Y}+d \alpha(t) \theta_{K X}}{|\theta|}
$$

or, $\hat{w}=\frac{\frac{1-\alpha(t)}{1+t} d t \theta_{K Y}+d \alpha(t)|\theta|}{|\theta|}$

Since, $|\theta|>0, d t<0$ and $d \alpha(t)<0, \hat{w}<0$.

And,

$\hat{r}=\frac{-\theta_{L X} d \alpha(t)-\frac{1-\alpha(t)}{1+t} \theta_{L Y} d t+d \alpha(t) \theta_{L Y}}{|\theta|}$

or, $\hat{r}=\frac{d \alpha(t)|\theta|-\frac{1-\alpha(t)}{1+t} \theta_{L Y . d t}}{|\theta|}$

Again, since $|\theta|>0, d t<0$ and $d \alpha(t)<0, \hat{r}>0$ iff $\frac{d \alpha(t)}{d t}<\frac{1-\alpha(t)}{1+t} \frac{\theta_{L Y}}{|\theta|}$ and $\hat{r}<0$ iff $\frac{d \alpha(t)}{d t}>\frac{1-\alpha(t)}{1+t} \frac{\theta_{L Y}}{|\theta|}$

- Hence Proposition-V is proved

\section{APPENDIX D}

Differentiating equation (25) w.r.t. $P$

$\beta \alpha\left(L_{g}\right)\left[P \frac{d X}{d L_{z}}+\frac{d Y}{d L_{z}}\right] \frac{d L_{z}}{d P}+\beta \alpha\left(L_{g}\right) \cdot X=w^{\prime} b\left(L_{z}\right) \cdot \frac{d L_{z}}{d P} \cdot L_{g}+w \cdot \frac{d L_{z}}{d P}+\frac{d w}{d P}\left(L_{z}+L_{g}\right)$ 
or, $\frac{d L_{z}}{d P}=\frac{\left[\beta \alpha\left(L_{g}\right) \cdot X-\frac{d w}{d P}\left(L_{z}+L_{g}\right)\right]}{w^{\prime}{ }^{\prime} \cdot L_{g}+w-\beta \alpha\left(L_{g}\right)\left\{P \cdot \frac{d X}{d L_{z}}+\frac{d Y}{d L_{z}}\right\}}$

here, $\frac{d w}{d P}<0$ and $w+L_{g} . w_{b}^{\prime}\left(L_{z}\right)=\Delta>0$ for stability of equilibrium $L_{z}$.

Setting $(P d X+d Y)=0$ from envelope condition we get,

$$
\frac{d L_{z}}{d P}=\frac{\left[\beta \alpha\left(L_{g}\right) \cdot X-\frac{d w}{d P}\left(L_{z}+L_{g}\right)\right]}{\Delta}>0
$$

Differentiating equation (25) w.r.t. $\beta$, for a given $P$ and using envelope condition one gets,

$\alpha\left(L_{g}\right) \cdot P \cdot X+\alpha\left(L_{g}\right) Y=\frac{d w_{b}\left(L_{z}\right)}{d L_{z}} \cdot \frac{d L_{z}}{d \beta} \cdot L g+w \cdot \frac{d L_{z}}{d \beta}$

or, $\frac{d L_{z}}{d \beta}=\frac{\left[\alpha\left(L_{g}\right)(P \cdot X+Y)\right]}{\Delta}>0$

Differentiating equation (25) w.r.t. $\beta$, for a given $\mathrm{P}$ and using envelope condition one we have,

$\beta \frac{d \alpha\left(L_{g}\right)}{d L_{g}} \cdot P X+\beta \frac{d \alpha\left(L_{g}\right)}{d L_{g}} . Y=w+L_{g} \frac{d w}{d L_{g}}+\frac{d w_{b}\left(L_{z}\right)}{d L_{z}} \frac{d L_{z}}{d L_{g}} \cdot L_{g}+w_{b}\left(L_{z}\right) .+w \cdot \frac{d L_{z}}{d L_{g}}+L_{z} \frac{d w}{d L_{g}}$

or, $\frac{d L_{z}}{d L_{g}}=\frac{\left[\beta \alpha^{\prime}\left(L_{g}\right)(P . X+Y)-\left[w+w_{b}\left(L_{z}\right)\right]-\left(L_{z}+L_{g}\right) \frac{d w}{d L_{g}}\right]}{\Delta}$

\section{End note}

1. Chan (2006) looks at the role of property rights and comparative advantage. Although similar in spirit, he does not deal with the factor-endowment approach. 
2. Analysis of corruption and related distortion in open economies starts with Krueger (1974) and Bhagwati (1982). Later papers by Hillman and Ursprung (1988, 1996) introduced explicit political economy angle to the trade related problems. Hillman (2003) summarizes research in this area. More recently Marjit, Ghosh and Biswas (2006), bring in the issue of corruption and trade reform in the context of a developing economy.

3. A paper by Lui ( 1985 ) is an interesting reference on this.

\section{$\underline{\text { References }}$}

- Anderson, J (2000) - Why do nations trade (so little)?, Pacific Economic Review, $5,2,115-134$.

- Anderson, J and D. Marcouiller (2002) - Insecurity and Pattern of Trade ;An Empirical Investigation - Review of Economics and Statistics, 84,2, 324352.

- Bhagwati, J (1982)- Directly Unproductive Profit Seeking (DUP) ActivitiesJournal of Political Economy, 90, 5, 988-1002.

- Chan, K. (2006) - Institutions and the Comparative Advantage of Nations-mimeo, City University of Hong Kong.

- De Jong E. and E. Udo (2006) - Is corruption detrimental to international trade mimeo, Radboud University, Nijmegan.

- Hillman, A and H. Ursprung (1988) - Domestic Politics, Foreign Interest and International Trade Policy - Amercian Economic Review, 78(4), 719745.

- ___ and ___ (1996) - The Political Economy of Trade Liberalization in transition - European Economic Review, 40(3-5), 783-794. 
- Hillman, A (2003) Public Finance and Public Policy - Cambridge University Press.

- Jansen, M and H. K. Nordas (2004) - Institutions, Trade policy and Trade flows Staff Working Paper ESRD, WTO, 2004 -02, Geneva.

- Jones, R.W. (1965) - The Structure of Simple General Equilibrium ModelsJournal of Political Economy, 73, 557-572.

- Kaufman, D and S. J. Wei (1999) - Does "Grease Money" Speed up the wheels of Commerce? - NBER WP. NO. 7093.

- Kommerskollegium, National Board of Trade - Trade and the fight against corruption annex 1-2, 2005-12-21, 100-457-05, 1-12.

- Krueger, A (1974) The political Economy of Rent-Seeking Society - $\underline{\text { Amercian }}$ Economic Review 64(3), 291-303.

- Lavalle, E (2006) - Governance, Corruption and Trade: A North-South Approach - mimeo, University Paris - Dauphine

- Lui, F (1985) - An Equilibrium Queuing Model of Bribery - Journal of Political Economy- 93(4), 760-781.

- Marjit, S, S. Ghosh and A. K. Biswas (2006) - Informality, corruption and trade reform - European Journal of Political Economy (forthcoming)

- Mauro, P (1995) - Corruption and Growth- Quarterly Journal of Economics- 110, $3,681-712$.

- OECD (2001)-

- Shleifer ,A and R. Vishny (1993) Corruption - Quarterly Journal of Economics$109,3,599-617$. 
- Trefler, D (1995) - The Case of Missing Trade and Other Mysteries - $\underline{\text { American }}$ Economic Review 85, 1029-1046.

- Wei S. J. (1997) - Why corruption is so much more taxing than tax? Arbitrariness Kills - NBER WP.NO. 6255. 


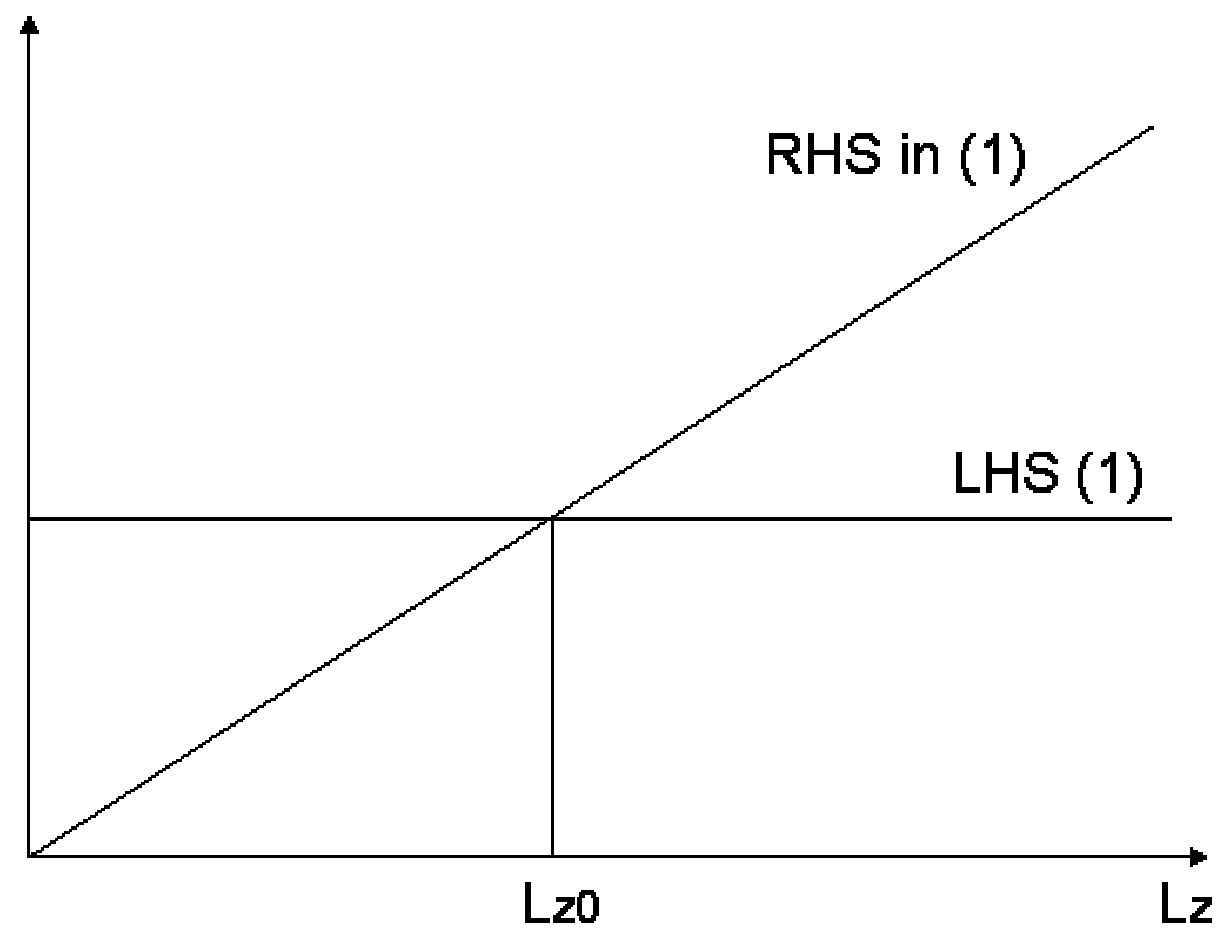

Figure - 1 


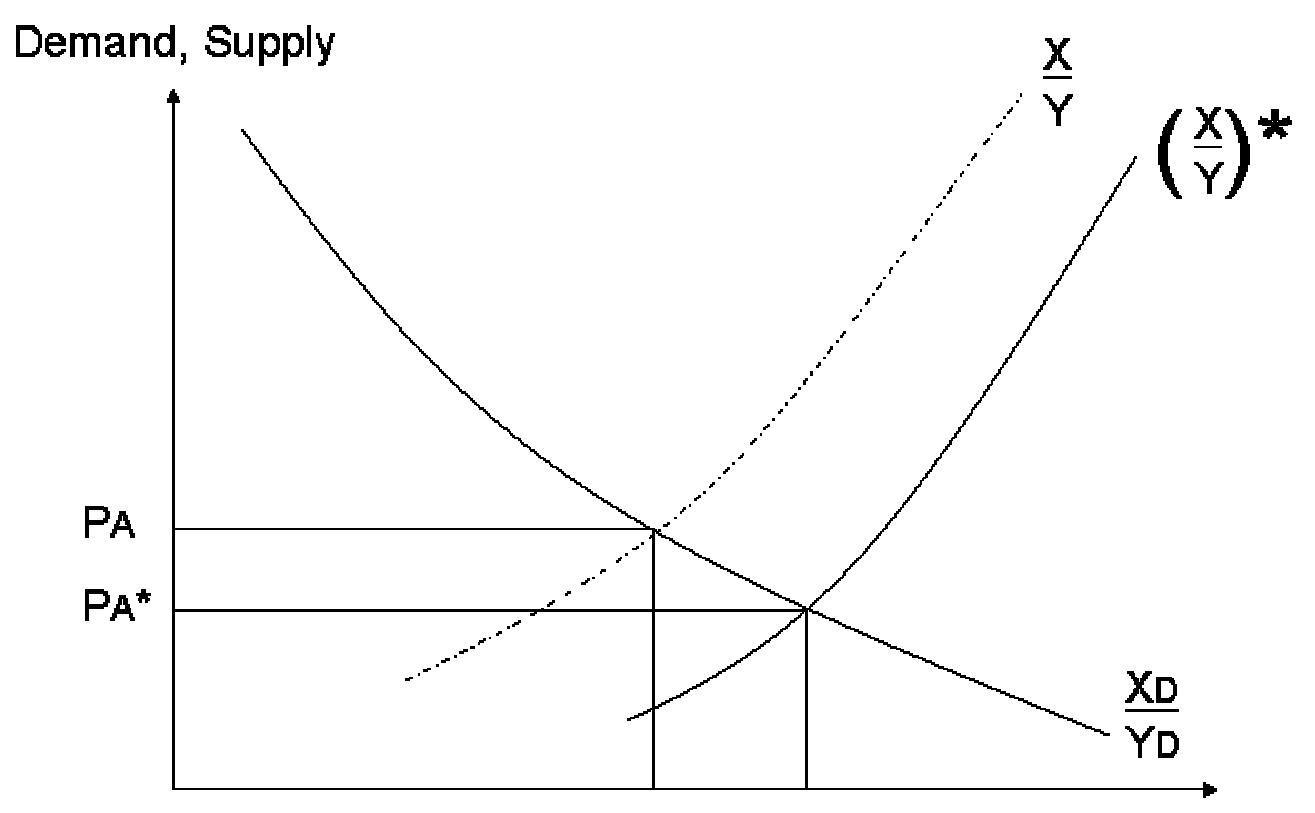

Figure - 2 


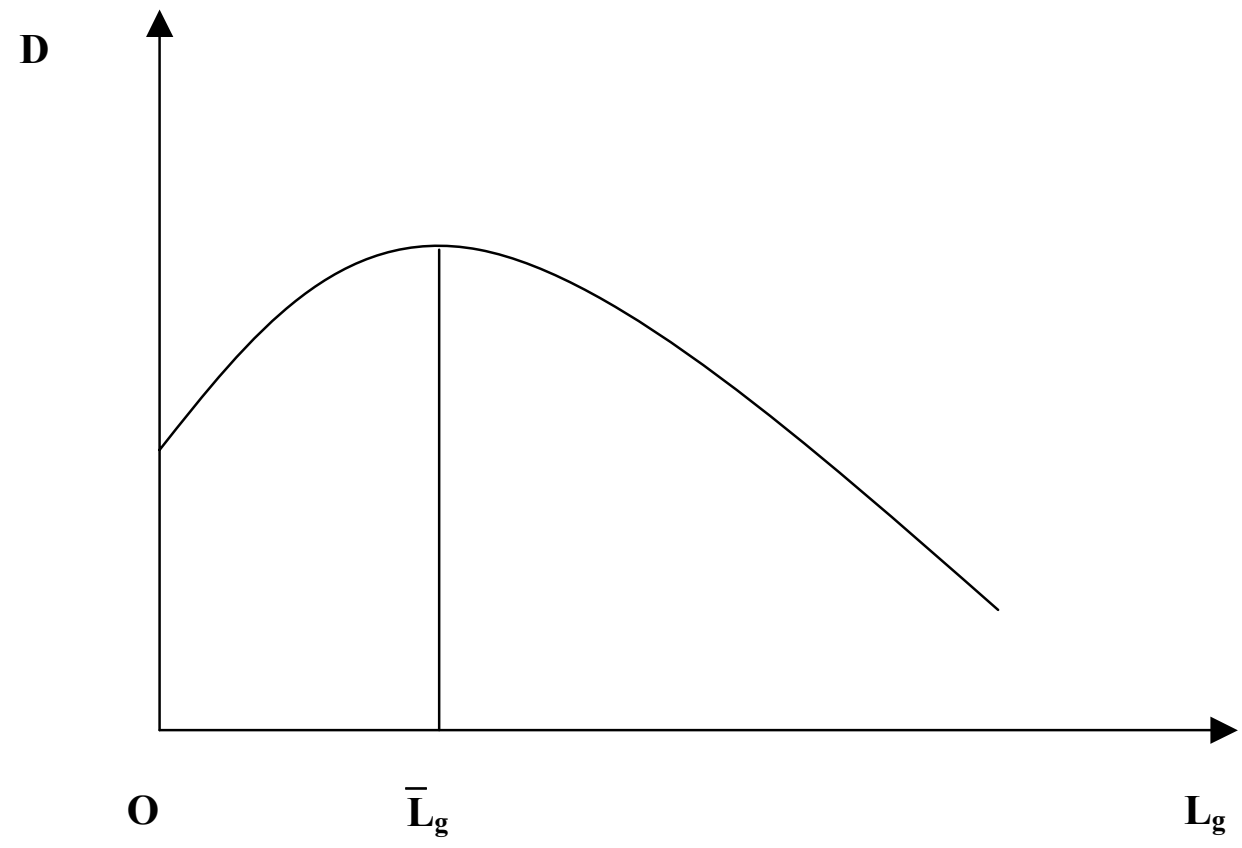

